\title{
Revisión conceptual de los aprendizajes de los niños y niñas como base fundamental de su desarrollo integral y multidimensional ${ }^{1}$
}

\section{Conceptual review of the learning of children as the foundation of their integral development and multidimensional'}

\author{
Nadia Milena Henao García*
}

\section{Resumen}

El artículo presenta una síntesis de la construcción del marco conceptual que fundamenta el proyecto investigativo "Aprendizajes relevantes para los niños y niñas menores de 4 años, según la opinión de diversos actores de algunos países latinoamericanos", que es coordinado por el Comité de la Organización Mundial de Educación Preescolar- Chile; además evidencia el proceso académico e investigativo hecho en la práctica. Se conceptualizan cuatro categorías de las que se partió para dicha construcción. La primera estaba enfocada al concepto de aprendizaje; la segunda al aprendizaje infantil desde la perspectiva actual; la tercera a la relación entre aprendizaje y educación; y la cuarta a la importancia de las comunidades educativas. Las cuatro categorías están basadas en la importancia que tiene brindar atención, formación y aprendizaje desde una perspectiva integral para los niños y las niñas en su primera infancia.

Palabras clave: Aprendizaje; Niños y niñas; Desarrollo; Atención; Construcción conceptual; Formación en investigación.

Licenciada en Educación Preescolar, Docente del programa Buen Comienzo. Alcaldía de Medellín, milenah02@gmail.com

Este artículo fue escrito con base en la construcción del marco conceptual, que sustenta el proyecto "Aprendizajes relevantes para los niños y niñas, según la opinión de diversos actores de algunos países latinoamericanos", proyecto coordinado por la OMEP de Chile y el Grupo de Investigación Senderos, desde la Línea de Investigación Infancia del Tecnológico de Antioquia - Institución Universitaria. 
Tea Nadia Milena Henao García

\section{Abstract}

This article is the synthesis of the conceptual framework of the research proyect entitled "relevant learning to children under four years old according to several performers from some Latin American countries", coordinated by the World Organization for Early Childhood Education at Chile. Practicing on research and academic process is also shown. Four categories emphasized on attention, training and learning from a global perspective for early childhood were used in this framework: I) learning concept, 2) childhood learning from current perspective, 3) relationship between learning and education and 4) the importance of educative communities.

\section{Keywords: Learning; Children; Development; Attention; Training.}

En este artículo se presenta una síntesis de la revisión bibliográfica realizada, con el fin de construir el marco conceptual del proyecto "Aprendizajes relevantes para los niños y niñas menores de 4 años, según la opinión de diversos actores de algunos países latinoamericanos". Dicho proyecto se encuentra coordinado por el Comité de la OMEP Chile, con la participación de varios países latinoamericanos desde los comités regionales, específicamente desde Colombia, por el Tecnológico de Antioquia - Institución Universitaria, como miembro activo de dicha organización. Su realización aporta al cumplimiento de las acciones de la OMEP que están referidas a la "promoción de estudios e investigaciones sobre la primera infancia”.

Como procedimiento investigativo $y$ académico, el propósito de este artículo es evidenciar que, a partir de la práctica investigativa se realizó la conceptualización del marco que sustenta el proyecto en mención y que este permitió afianzar uno de los objetivos del Tecnológico de Antioquia con sus estudiantes, en relación con la formación en investigación. De este trabajo se puede inferir que se tiene hoy una mirada crítica, reflexiva y propositiva de la formación como docentes, que permite, según Correa:
La utilización y puesta en marcha de los conocimientos propios del objeto de formación, adquirir nuevas maneras de comprender la realidad educativa, reconocer los dominios conceptuales y procedimentales, relativizar muchas de sus interiorizaciones teóricas y tomar conciencia de los límites que existen en la práctica y los retos e innovaciones para enfrentarlay acercarse con mayor seguridad a los problemas del conocimiento y de los escenarios educativos; ubicándose como sujeto activo en este proceso formativo (2010, p. 2).

El artículo se estructura en tres partes con el fin de dar respuesta, tanto a la construcción conceptual propia de un acto investigativo, como al propósito planteado desde la práctica: la primera hace referencia a los materiales y los métodos utilizados para la construcción del marco conceptual del proyecto investigativo y del presente artículo; la segunda, la construcción desde cuatro categorías; y, la tercera, las conclusiones y las referencias.

\section{Hacia la búsqueda de soporte bibliográfico y conceptual}

Para la construcción del marco conceptual del proyecto investigativo "Aprendizajes

2 En adelante se entenderá que cuando se hable de niño(s), se hace referencia a los niños y las niñas. 
Revisión conceptual de los niños y las niñas con base fundamental de su desarrollo integral y multidimencional TdeA

relevantes para los niños y niñas, según la opinión de diversos actores de algunos países latinoamericanos", se tuvieron en cuenta cuatro categorías; la primera de ellas hace referencia al concepto de aprendizaje, cómo se ha transformado y sustentado en teorías o enfoques de diferentes autores. La segunda categoría es aprendizaje infantil desde la perspectiva actual. Allí se retoman los aportes hechos por la neurociencia y el enfoque pedagógico desarrollista. La tercera categoría retoma la relación que existe entre aprendizaje y educación, vista desde una atención y formación integral y multidimensional de los niños, y cómo puede fundamentarse la educación inicial en un enfoque pedagógico desarrollista o Escuela nueva. La cuarta categoría está referida a las comunidades educativas y muestra que los contextos y agentes educativos que rodean al niño son corresponsables en la atención y educación afectuosa y en la movilización de aprendizajes relevantes, que se les brinden a los niños en su primera infancia.

La búsqueda de información, que soportan las anteriores categorías, realizadas por medio de un rastreo bibliográfico en múltiples textos, y se encontró información en relación con los aprendizajes dados en la primera infancia y con las políticas públicas gestadas para garantizar una atención y formación integral de los niños, además de la función que cumple cada contexto en el que se desenvuelve el niño, entre otros aspectos, que serán mostrados en el transcurso del artículo. De otra parte, también se utilizaron otros medios para la obtención de la información, como bases de datos para hacer una construcción coherente, clara y completa de las categorías y, en general, del marco conceptual del proyecto investigativo.

\section{Cuatro categorías para hablar de aprendizaje en la primera infancia:}

\section{Categoría 1. Concepto de Aprendizaje}

El aprendizaje, según Papalia, es un "cambio relativamente permanente en el comportamiento que se produce a través de la experiencia" (1998, p. 217). Por esta razón dicho concepto se relaciona con el de desarrollo y, por ende, con los procesos de madurez de cada ser humano. Para entender lo anterior es preciso decir que el desarrollo es un cambio constante de aspectos físicos y cerebrales, que se dan a través del tiempo, y permiten la adaptación al ambiente para lograr los aprendizajes.

La conexión que existe entre desarrollo y aprendizaje se puede evidenciar en cada una de las capacidades que va adquiriendo el ser humano a lo largo de su vida y que, constantemente, van aumentando su grado de dificultad y exigencia, según el entorno en el que se encuentre y las demandas. Para tener claridad de cómo se da cada uno de estos procesos, es necesario hacer un recorrido y un recuento de las teorías o enfoques planteados por psicólogos, neurólogos, pedagogos, entre otros expertos, y que han servido de base para construir nuevas teorías, que se fundamentan en las necesidades individuales y sociales del contexto actual.

Algunas de las teorías y enfoques más relevantes en estos ámbitos, enmarcadas dentro de distintas perspectivas, son:

\section{Perspectiva psicoanalítica:}

\section{- Teoría psicosexual de Freud:}

En el texto de Papalia (1998), Se plantea el enfoque de Freud desde un enfoque 
emocional del ser humano. Allí se argumenta que "la personalidad se forma en los primeros años de vida, cuando los niños enfrentan conflictos entre sus necesidades biológicas innatas, relacionadas con la sexualidad y las exigencias de la sociedad" (p. 23). Desde esta perspectiva, el autor pretende hacer evidente que la satisfacción de las necesidades hacen que el sujeto potencie aspectos de su personalidad, que Freud relaciona con la sexualidad, pero, a su vez, dice que esta satisfacción de necesidades están sujetas a unas exigencias sociales (costumbres, cultura, normas, etc.) que hacen que el sujeto las reprima, lo que trae consigo desórdenes emocionales en la edad adulta.

Por otra parte, la teoría freudiana define unos estadios (estadio oral (0-1 año), estadio anal (1-3 años), estadio fálico (3-6 años), estadio de latencia (6-11 años) y estadio genital (adolescencia y edad adulta), que reflejan la concepción del autor en el sentido de que, a medida que se desarrolla el sujeto, éste va adquiriendo nuevas conductas "aprendizajes" que dependen de un período de edades y de las relaciones tempranas del ser humano.

\section{Perspectiva cognoscitiva:}

\section{- Teoría cognoscitiva de Piaget:}

Se centra en lo intelectual-cognitivo del ser humano que se da por medio de estadios, según la edad (estadio sensorio-motriz (0-2 años), estadio preoperacional (2-7 años), estadio de operaciones concretas (7-12 años) y estadio de operaciones formales (12 años-en adelante). Esta teoría plantea que "los cambios en el pensamiento del niño conducen a una habilidad creciente para adquirir y utilizar el conocimiento a partir de su mundo". Papalia, por ello, el niño es asumido como un sujeto activo.

Piaget plantea que de estos conceptos se puede concluir que el paso de un estadio a otro y el desarrollo del intelecto son las bases centrales del aprendizaje. Esta teoría la retoma Palacios (1999, p. 45), quien despliega los conceptos piagetanos de la siguiente manera: Esquema (permite identificar los objetos y situaciones y su funcionamiento); Asimilación (cuando ya hay un esquema presente la conducta se repite con otros objetos que tengan las mismas características); Acomodación (es cuando un esquema preexistente no responde a las características de un objeto, se produce un desequilibrio, lo que implica modificar el esquema previo); y Adaptación (es cuando se logran los procesos anteriores y se permite que la persona maneje la nueva información en la resolución de problemas.

\section{- Enfoque del procesamiento de la información:}

Según Papalia, este enfoque se encarga de "analizar los procesos mentales subyacentes en el comportamiento inteligente, para entender el desarrollo cognoscitivo". Los procesos cognitivos o mentales a los que se hace alusión son los encargados de llevar al sujeto al aprendizaje y están relacionados con: la atención, la memoria, la percepción, la sensación y la concentración, que, además, permiten recibir la información, seleccionarla y asimilarla, luego, adaptarla a las estructuras mentales preexistentes, las retiene de forma organizada y, por último, usa la información en la resolución de problemas, mediante la cognición superior o compleja, como el pensamiento, el lenguaje y la inteligencia. 
Robbie Case (1998) teórico e investigador del procesamiento de la información, citado por Papalia, sostiene que: "los niños que se desarrollan a nivel cognoscitivo se vuelven más eficientes que mediante el equilibrio" (p. 38). Este autor sostiene que el niño, cuando practica actividades como leer o escribir, se vuelve más hábil, es decir, puede llevar a cabo acciones de manera automática y mecánica.

\section{Perspectiva contextual:}

\section{- Teoría Sociocultural de Vigotsky:}

Dicha teoría está enfocada en el sujeto como ser social y cultural, Vigotsky (1998), dice que ve "el desarrollo del ser humano dentro de un contexto social" (p. 40), es decir, se plantea el hecho de que primero aprendemos del entorno social y cultural, para luego desarrollarnos internamente.

Para este autor los procesos cognitivos superiores tienen gran influencia en la mediación de las relaciones entorno-sujeto, pues, para él, la conducta no está determinada por los estímulos sino por (el lenguaje, el pensamiento y la inteligencia). En esta perspectiva, se pretende mostrar que el sujeto se apropia de los instrumentos insertos en la cultura, para provocar su propio desarrollo. Palacios (1999, p. 58) retoma la teoría de Vogotsky y explica que dicho proceso debe tener en consideración, como mínimo, tres niveles de análisis:

- Los procesos psicológicos superiores tienen una génesis social y se encuentran dentro del individuo solo después de que éste los ha encontrado en su relación con el entorno sociocultural. Lo anterior significa concebir al individuo como un ser que va de lo social a lo individual.

- Otro aspecto fundamental de esta teoría se centra en la mediación que hace el adulto con el niño, pues, el primero es el encargado de conducir el aprendizaje, para que, posteriormente, el niño sea capaz de hacer sus cosas de manera autónoma.

- Por último, Vigotsky indica que el paso de lo interpsicológico a lo intrapsicológico depende de la capacidad para diferenciar la zona de desarrollo actual (lo que la persona es capaz de hacer por sí misma) y la zona de desarrollo próximo (lo que no puede hacer por sí misma, pero que puede aprender a hacer, si alguien la guía).

\section{Perspectiva ecológica:}

\section{- Enfoque ecológico de Bronfenbrenner:}

Bronfenbrenner (1999, pp. 55-56): en su enfoque ecológico, le da importancia al medio ambiente porque sostiene que éste influye en el desarrollo del ser humano, pues, argumenta que éste es complejo en el que están en juego gran cantidad de factores que no pueden ser reducidos o parcializados. Las interacciones son bidireccionales y afectadas desde múltiples entornos, $y$, para entenderlo, es importante comprender a cada persona dentro de unos sistemas, que se dividen en:

- Microsistema: Son los contextos inmediatos en los que la persona se encuentra y vive experiencias significativas, tales como: la familia, la escuela y los amigos.

- Mesosistema: Interconexión entre los 
diferentes microsistemas (escuela-familia, familia-amigos, etc.).

- Exosistemas: Escenarios que no contienen al sujeto como tal, pero sí lo afectan (familia extensa, servicios de salud, etc.).

- Macrosistema: Valores, leyes, costumbres, pautas y cultura de la sociedad en general.

- Cronosistema: Abarca el cambio o permanencia de una persona a través del tiempo.

\section{Perspectiva del aprendizaje}

\section{- Conductismo o teoría del aprendizaje tradicional:}

El conductismo es una corriente de la psicología que estudia el comportamiento observable (la conducta), la cual es aprendida por unos estímulos-respuestas que provienen del entorno. Esta corriente cuenta con dos exponentes, quienes tienen dos posturas distintas pero, a la vez, interrelacionadas. Ellos son:

- El condicionamiento clásico de Watson, citado por Papalia, "es un tipo de aprendizaje en el que el animal o la persona aprende una respuesta ante un estímulo que originalmente no la produciría, después de que este estímulo se asocie repetidas veces con uno que produciría la respuesta" es decir, un estímulo que viene del medio hace que el sujeto produzca una respuesta inconsciente, después de producir la misma respuesta varias veces, frente al mismo estímulo, la respuesta se convierte en consciente.
- El condicionamiento operante

de Skinner, a diferencia del condicionamiento clásico, en esta corriente, el sujeto produce una respuesta accidental, como: reír, llorar, gritar, etc., lo que hace que otra persona entre a reforzar dichas respuestas, es decir, si ríe, la otra persona también se ríe. De esta manera, el niño interioriza el hecho de que él hará lo mismo que la otra persona. Lo anterior permite establecer que todo acto tiene una consecuencia, bien sea positiva o negativa y que se produzca o no una determinada conducta.

Según el conductismo, tanto el clásico como el operante, el aprendizaje es independiente de los factores internos como la edad, lo físico y lo mental, porque sostiene que el aprendizaje está ligado a factores externos al sujeto, como los estímulos recibidos y que se convierten en conductas o comportamientos aprehendidos y observados por los demás.

\section{- Teoría del aprendizaje social (social- cognoscitiva) de Bandura:}

Aunque esta teoría tiene sus bases en el conductismo, se diferencia en varios aspectos; el primero es que tiene en cuenta al sujeto como activo en la adquisición de los aprendizaje y no como receptor del mismo; el segundo es que considera que experimentar en animales no explica el comportamiento humano; y el tercero es que reconoce la influencia de los procesos cognitivos y de la observación dentro de un contexto social como base del aprendizaje. Esta propuesta teórica se puede sintetizar con la cita que hace Papalia de que "los niños aprenden comportamientos sociales al observar e imitar modelos, por lo común, de los padres" (p. 33). 
Esto muestra que la observación ejerce un papel fundamental en el aprendizaje, ya que es a partir de la observación que los niños empiezan a construir comportamientos inmersos en un contexto social como la familia, la escuela, etc., pero esto no implica que el sujeto solo sea receptor y reproductor de lo observado, sino que él mismo sea capaz de controlar las conductas aprendidas, por medio de los procesos cognitivos para configurar su personalidad y autorregulación.

\section{- Teoría del aprendizaje significativo de Ausubel:}

En su teoría, Ausubel (2002), plantea que lo realmente importante para adquirir un aprendizaje es tener en cuenta lo ya aprendido, pues, afirmaba, de acuerdo con Zubiría, que "si tuviera que reducir toda la psicología educativa a un solo principio, enunciaría este: el factor más importante que influye en el aprendizaje es lo que el alumno ya sabe. Averígüese esto, y enséñese consecuentemente" (p. 165).

Para este autor, el objetivo principal del aprendizaje es lograr que el estudiante adquiera unos conocimientos claros, estables y organizados. También, afirma que, según como se incorpore la nueva información, se pueden identificar dos tipos de aprendizaje:

- Aprendizaje memorístico: se produce cuando se captura información de forma mecánica y arbitraria, sin ningún tipo de comprensión y significación de la misma.

- Aprendizaje significativo: se produce en el momento en el que el sujeto es capaz de comprender la información recibida y relacionarla con lo que ya sabía para construir nuevos significados.
Esta teoría presupone el hecho de que el niño puede aprender de forma autónoma, es decir, un aprendizaje basado en el descubrimiento que él hace de su mundo, o por medio de un aprendizaje guiado por un docente, denominado también aprendizaje por recepción.

Después de hacer este recorrido por las corrientes y teorías del aprendizaje, se puede inferir que se han transformado gracias a que anteriormente se hacía énfasis en unos procesos lineales y secuenciales, pero después se empezó a hacer conciencia de la necesidad de relacionar tanto lo intrínseco como lo extrínseco a cada sujeto; en consecuencia, es preciso ver las capacidades del ser humano para pensar reflexiva y críticamente sobre los aprendizajes adquiridos. Francisco Cajiao (2005) define el aprendizaje como “... un ejercicio constante de interacción con el medio circundante que involucra en el ser humano la capacidad sensorial y todas las facultades intelectivas que de manera genérica se denominan el pensamiento. Cada nuevo aprendizaje realizado por una persona modifica de algún modo todo lo que ya sabía anteriormente y le permite nuevas experiencias...” (pp. 73-74). Esta definición permite sintetizar lo que realmente implica el aprendizaje: pensar para no repetir mecánicamente la información.

\section{Categoría 2. Aprendizaje infantil desde la perspectiva actual}

Algunas investigaciones han demostrado, según el Ministerio de Educación Nacional -MEN- (2009) que "el desarrollo del cerebro ocurre durante los tres primeros años de vida y dependen, en parte, del entorno en el que el niño crece, de su nutrición, su salud, 
la protección que recibe y las interacciones humanas que experimenta” (p. 8), por tal motivo dicha etapa es determinante para el desarrollo del sujeto durante toda su vida, desde lo social, lo cognitivo, lo emocional y lo físico.

Si se apoya teóricamente en la neurociencia, encargada de estudiar el sistema nervioso $\mathrm{y}$ sus funciones, se puede determinar que dicho sistema se encuentra estrechamente relacionado con los procesos de aprendizaje de cada sujeto, debido a que modelan el cerebro y, como lo plantea De la Barrera \& Donolo (2009): "la enseñanza y la formación de la niñez son las encargadas de ofrecer estímulos intelectuales necesarios para el cerebro y su desarrollo, ya que permiten el despliegue de las capacidades cognitivas y hacen más viables los aprendizajes” (p. 6). Es menester aprender a reconocer los factores internos como determinantes del desarrollo y los externos como causas principales del mismo.

$\mathrm{Si}$, se profundiza en los estudios de la neurociencia queda claro que los llamados periodos críticos para el crecimiento del cerebro y la adquisición de los aprendizajes, están ubicados en los tres primeros años de vida. Según Barreda (2000):

Durante este período, el cerebro no sólo es especialmente receptivo al adquirir cierto tipo de información sino que además necesita de ella para lograr las conexiones neuronales en forma apropiada. Los estímulos emocionales, afectivos, verbales, visuales y auditivos, orientan y conducen el complejo proceso de interconexión de las neuronas, que posteriormente va a permitir un aprendizaje normal.
Es así que, en este periodo, se den las bases para el perfeccionamiento psicomotor $y$ cognitivo, los inicios de la comunicación y el lenguaje y el desarrollo socio-afectivo.

Tanto lo interno (la estructura cerebral), como lo externo (los estímulos), juegan papeles preponderantes en el crecimiento de los niños, desde las múltiples dimensiones y, más aún, en sus primeros años de vida, ya que es en estos primeros años cuando el sistema nervioso construye las conexiones que garanticen el aprendizaje. Esta construcción se da especialmente hasta los seis años de vida.

Hemos visto que el desarrollo y el aprendizaje están interrelacionados para garantizar el desarrollo integral y multidimensional del ser humano. Por tal razón, es preciso crear ambientes enriquecidos con estímulos que surgen desde la educación inicial, puesto que es allí que se genera un acompañamiento intencional, organizado y estructurado para procurar las potencias que estimulen las habilidades, capacidades y destrezas del niño.

La educación inicial surge como una posibilidad de ofrecer a la primera infancia las condiciones para una atención y formación integral en las que haya aprendizajes armónicos. A partir de esta necesidad aparece como opción la pedagogía activa o la escuela activa, que se originó, como lo plantea Zubiría (2002) debido a "diversos factores de orden histórico, social y científico para crear las condiciones que produjeron una profunda revolución en la concepción de la pedagogía y la educación desde fines del siglo XIX, los cuales conducirán a la aparición de la escuela activa como una nueva manera de entender el aprendizaje, la educación y el desarrollo del niño" (pp. 105-106). 
Estos factores que dieron origen a la escuela activa, develaron la importancia que adquiere el niño como sujeto activo del proceso de aprendizaje y enseñanza, porque permiten pensar la interacción con el medio social y físico del que hace parte el sujeto para que se reconozca como autónomo y con las capacidades suficientes para la reflexión, la observación, la experimentación y para que descubra nuevas formas de conocimiento por medio del pensamiento.

El aprendizaje infantil, desde la perspectiva actual, debe estar orientado a favorecer no solo la perfección de las estructuras cerebrales, sino, también, a permitir el acceso a nuevas formas de conocimiento mediadas por estrategias pedagógicas que resalten la experiencia individual y las relaciones con el entorno, que dejen a un lado los procesos memorísticos del modelo tradicional y que den paso al desarrollo del pensamiento, en el que se originan los metacognitivos como la autorregulación de la información proveniente del exterior $y$ generar autoconocimiento y autocontrol de los aprendizajes adquiridos.

El aprendizaje se ha convertido en una acción que está estrechamente relacionada con el desarrollo, de ahí la importancia que tiene conocer cómo es y ha sido el cada niño. Dicho reconocimiento se puede dar por medio de la observación de actividades cotidianas, pedagógicas, lúdicas y recreativas, que den cuenta de las capacidades de él según su edad $\mathrm{y}$ condiciones físicas y ambientales.

Para que lo anterior se dé es pertinente mirar los factores que intervienen en el proceso de aprendizaje de los niños y que, sin ellos, sería imposible generar un desarrollo pleno del ser
humano.Losfactores que deben estarinmersos dentro del modelo desarrollista que nace del enfoque pedagógico activo, como una de las bases de la educación inicial, son:

- Considerar, según la definición que da el MEN (1995) a la educación como "señalar caminos para la autodeterminación personal y social, y como el desarrollo de la conciencia crítica por medio del análisis y transformación de la realidad” (p. 27). Así es que el sujeto va aprendiendo a descubrir por sí solo nuevos conocimientos y experiencias para resolver problemas de su cotidianidad, orientados por los agentes educativos o significativos y los entornos de los que participa el niño.

- El currículo, como lo plantea González es un "conjunto de responsabilidades de la escuela para promover una serie de experiencias en el alumno, o una serie de experiencias recreadas por los estudiantes a través de las que pueden desarrollarse" ( $p$. 6). Este currículo debe ser asumido desde el contexto institucional o escolar.

- El docente o el agente educativo como un mediador o guía en el aprendizaje de los niños, capaz de generar ambientes y experiencias motivadoras para lograr que el niño alcance el crecimiento de sus estructuras de pensamiento. Además, que la relación que establezca el agente educativo con el estudiante debe estar mediado por el diálogo permanente, la cooperación y el apoyo.

- Los espacios significativos, entendidos, según el MEN como "ambientes de aprendizaje estructurados para generar 
múltiples experiencias para los niños y las niñas" (2009, p. 22). Estos espacios deben estar enfocados a despertar la curiosidad, la reflexión, el descubrimiento, la experimentación y la resolución de problemas. Deben, además, dar prioridad al aprendizaje sobre la enseñanza, pues es preciso comprender que cualquier actividad, tarea y experiencia, deben buscar oportunidades para que los niños aprendan, conozcan y piensen. En este sentido cabe resaltar unas estrategias metodológicas que se pueden utilizar para garantizar los aprendizajes, tales como AMEI-Waece (2005, p. 121):

- Permitir que los niños exploren activamente con todos los sentidos.

- Descubrir las relaciones por experiencia directa con los objetos.

- Estimular que el niño hable de lo que hace.

- Señalar relaciones entre los objetos.

- Dejar que los niños hagan las cosas por sí solos, aunque tarden.

- Brindar opciones si el niño necesita ayuda.

- Permitir que los niños manipulen, transformen y combinen materiales.

- Ampliar el uso y funciones de materiales y objetos.

- Provocar acción con los materiales.

- Seleccionar, entre los niños y los agentes, las actividades, objetivos y los materiales.

- Ayudar al niño a reconocer qué ha hecho y cómo lo ha hecho.

- Referir preguntas o problemas de un niño a otro para generar un aprendizaje cooperativo y social.

- Ofrecer alternativas cuando el niño está en una acción repetitiva.

- El niño debe ser el centro del aprendizaje por su carácter activo, es decir, un buscador de significados, crítico, inventor e indagador, en contacto permanente con la realidad. Por otro lado, debe ser visto por el agente educativo como un ser integral y multidimensional.

- Y, por último, encontramos la evaluación, que se debe generar por procesos. Además, debe tener un carácter cualitativo, objetiva, flexible y mediada por la observación e instrumentos para la recolección de la información, tales como el diario y el anecdotario, en el caso de ser realizada dentro de un contexto institucional.

Con estos factores resueltos se logrará que los aprendizajes que se les proporcionen a los niños en su primera infancia cuenten con un acompañamiento integral, responsable y respetuoso de las individualidades, y que se reconozca la diversidad cultural, étnica, física, cognitiva, social y afectiva. En este sentido, se asume que el niño se debe hacer partícipe, que exprese sus sentimientos y acciones, que generen espacios para la reflexión y la interacción con el entorno social y físico. 
Permitir la ejecución de esta propuesta implica volver sobre los cuatro aprendizajes fundamentales dentro del contexto actual, que se convertirán en la vida de cada persona, en los pilares del conocimiento y que, de acuerdo con Delors, citado por el MEN (1995, pp. 17-19): son:

- Aprender a conocer: es adquirir los instrumentos para comprender, descubrir y conocer el mundo que nos rodea, es decir, aprender a aprender.

- Aprender a hacer: lo cual permite influir en el entorno, solucionar problemas, planificar, elaborar y realizar tareas, a partir de la observación y experimentación con lo que hay y sucede a su alrededor.

- Aprender a vivir juntos: es poder participar, cooperar con los demás, descubrir al otro, ser solidario y estar en la capacidad de ponerse en el lugar del otro, partiendo del reconocimiento de sí mismo.

- Aprender a ser: permite recoger elementos de los anteriores aprendizajes; su función se centra en permitir la libertad de sentimientos, pensamientos y acciones para llevar a la construcción del destino de cada uno.

\section{Categoría 3. Aprendizaje y educación}

La educación es una función social que busca responder a dos interrogantes: ¿Qué clase de seres humanos se quiere formar? ¿Qué sociedad se desea?, a partir de estos interrogantes surgen los llamados modelos pedagógicos que intentan responder con sus propios postulados y con el despliegue de sus teorías. Entre ellas, se destacan, por ejemplo, de acuerdo con Zubiría (1999, p. 39):

- La teoría psicológica: se enfoca en la dimensiónindividualyexplicaeldesarrollo de la personalidad y de los intereses.

- La teoría sociológica: explica la dimensión social y las relaciones que establece el individuo con el entorno.

- La teoría antropológica: se encarga de explicar la dimensión cultural del hombre.

- La teoría pedagógica: se convierte en una propuesta que se basa en modelos pedagógicos, de acuerdo con la función que se le asigne a la educación, bien sea psicológica, social o antropológica. Intenta responder las preguntas relacionadas con el para qué se enseña, "el propósito de la educación"; el qué se enseña, "los contenidos"; el cuándo se enseña, "la secuenciación”; el cómo se enseña, "la metodología"; el con qué se enseña, "los recursos didácticos"; si se cumplió o se está cumpliendo el propósito de la educación, "la evaluación".

En estas teorías se sustenta el Modelo pedagógico desarrollista y la Escuela Nueva, con una tradición histórica desde el momento en que se hizo consciente de la importancia de educar a los niños desde edades tempranas. La educación de la primera infancia, denominada por el Ministerio de Educación Nacional de Colombia como educación inicial, tiene sus antecedentes en las obras de algunos pedagogos y teóricos, de los que se destacan Comenio, Rousseau y Pestalozzi. 
Ce. Nadia Milena Henao García

El primero de ellos, Comenio, (1592-1670), citado por Zubiria (2002) a través de su obra Didáctica magna, expresa la importancia del "tránsito hacia la acción y reivindicación de lo natural en la enseñanza" (p. 107). Su método pedagógico tenía como base los procesos naturales del aprendizaje: la inducción, la observación,lossentidosylarazón.Élplanteaba que la enseñanza debía ser global, es decir, para todos y que, además, debía empezar desde la niñez para valorar en su sentido práctico las primeras relaciones que el niño establece con su familia.

El segundo, Rousseau, (1712-1778), a través de su obra Emilio, hace un gran aporte a la Escuela Nueva. Rousseau, dice Zubiría "se enfrentaalautoritarismo, al "intelectualismo" $y$ a la desnaturalización de la Escuela tradicional y proclama el principio del crecimiento “espontáneo"y “natural” delniñoylanecesidad de concebirlo como un ser independiente y no como un "adulto en miniatura" (2002, p. 107). Como Emilio no fue una obra referida únicamente a la pedagogía, planteaba que la educación debería educar al ciudadano paraque éste conforme una nueva sociedad.

El tercero, Pestalozzi, (1746-1827), recoge los planteamientos de Rousseau, pero dista de éste cuando expresa la trascendencia que tiene la vida social, defiende la autoeducación para "conseguir laautonomíayel desarrollointegral del hombre”. Para este autor la escuela debería enseñar un oficio que integre a los niños de escasos recursos y que los prepare para la vida social.

La educación inicial no es un concepto nuevo porque fue usado hace muchos años atrás y aunque eran básicos los planteamientos, permitieron abrir los horizontes para concebir al niño como ser integral y multidimensional. Para lograr esta concepción se debió ampliar la perspectiva inicial que sólo miraba la formación o educación preescolar o inicial, para las edades de 5 a 6 años de edad y dejaba a un lado la población que va desde el nacimiento hasta los 4 años.

Desde esta perspectiva, y en el marco de las políticas públicas que se han gestado en torno a la infancia en las últimas décadas, se empieza a hablar de primera infancia que se define por el Congreso de la República de Colombia como:

La etapa del ciclo vital en la que se establecen las bases para el desarrollo cognitivo, emocional y social del ser humano. Comprende la franja poblacional que va de los cero (0) a los seis (6) años de edad. Desde la primera infancia, los niños y las niñas son sujetos titulares de los derechos reconocidos en los tratados internacionales, en la Constitución Política y en este Código (2006, p. 21, art. 29). Son derechos impostergables de la primera infancia, la atención en salud y nutrición, el esquema completo de vacunación, la protección contra los peligros físicos $\mathrm{y}$ la educación inicial. En el primer mes de vida deberá garantizarse el registro civil de todos los niños y las niñas.

Con esta normativa estatal se empieza una reestructuración de la educación preescolar y se hace presente el concepto de Educación inicial que favorece el acceso desde el nacimiento hasta los seis años, pues, como se ha mencionado, el desarrollo y el aprendizaje deben ser integrales desde el mismo momento de nacer. De acuerdo con Reveco (2006):

... para aportar desde la educación 
Revisión conceptual de los niños y las niñas con base fundamental de su desarrollo integral y multidimencional TaleA

a este desarrollo normal se requiere reconocer: a) Que la Educación Infantil es una etapa educativa con identidad propia y que hace efectivo el derecho a la educación; b) Que la Educación Infantil debe comenzar desde el nacimiento, con el fin de lograr aprendizajes, el desarrollo integral de la persona y prevenir futuras dificultades; c) Que la Educación Infantil integral tiene un efecto positivo en la reducción de las desigualdades socioeconómicas y de aprendizaje; d) Que el trabajo educativo con la niñez debe sustentarse en las características de la infancia y, por ello, se debe enseñar a través del juego, en la medida que descubren que es un modo natural de aprendizaje; e) Que se debe enseñar a partir del interés de los alumnos, así aprenderán fácilmente...

La educación inicial constituye uno de los pilares sobre los que se debe impulsar una transformación social, puesto que en ella se da, como lo plantea el MEN, "un proceso permanente y continuo de interacción y relaciones sociales de calidad, pertinentes $\mathrm{y}$ oportunas, que permiten a los niños potenciar sus capacidades y desarrollar sus competencias"... De acuerdo con el MEN $(2009$, p. 8$)$ el ciclo de vida desde el nacimiento hasta los 6 años es esencial para el desarrollo:

- Físico, emocional, social y cognitivo.

- De habilidades para pensar, hablar, razonar y aprender.

- De comportamientos presentes y futuros.

Los cambios que requiere nuestra sociedad ameritan una intervención directa, integral y continua sobre la educación desde la primera infancia. Para el Ministerio de Educación Nacional de Colombia, citando a Alvarado y Cano (2006):

Educar a un niño significa abrirle el mundo y ponerlo a su alcance; significa, también, ayudarle a derribar muchas de las barreras que pueden impedirle proyectar su vida y trazarse un derrotero para realizar ese proyecto. En cada período vital, la educación interpreta estos dos propósitos tomando en cuenta las posibilidades e intereses de los niños, los jóvenes y los adultos. En la primera infancia, la apertura del mundo representa para los niños el descubrimiento de sí mismos, de su propio cuerpo como distinto de lo que los rodea y, principalmente, el encuentro con el cuerpo social representado por su familia, los demás agentes educativos y sus pares, así como la apropiación de los medios fundamentales a los cuales recurrirán, reiteradamente, a lo largo de su existencia.

En este sentido, y con el principio de integralidad, es decir, la relación de interdependencia mutua entre los derechos y la práctica de su ejercicio, cualquier modalidad de educación en los primeros años que promueva la construcción de aprendizajes, debe tener en cuenta premisas básicas (MENICBF; 2007), tales como:

- Considerar al niño y a la niña como gestores de su propio desarrollo, a los padres y cuidadores como acompañantes afectuosos e inteligentes durante su vida.

- El aprendizaje es un elemento central en el desarrollo, que posibilita la adquisición de conocimientos, competencias, aptitudes, 
hábitos y valores.

- Fortalecimiento de la función de la familia como primer educador y como corresponsabledelaeducación delaprimera infancia.

- Afecto y buen trato, como factores esenciales que permitan establecer vínculos afectivos, que potencien lo físico, psicológico y social de los niños y niñas.

- Prestación conjunta de los servicios de educación, salud, protección $\mathrm{y}$ participación, basados en metodologías y contenidos en espacios que respondan a las necesidades y características de los niños y niñas hasta los 6 años.

- Ambientes protectores que reúnan condiciones de infraestructura y logística para favorecer una atención pertinente $y$ adecuada.

- Agente educativo formado y formador, modelo de referencia para el niño, investigador en la acción y dinamizador de las comunidades educativas y junto con la familia, diseñador, implementador y evaluador de los procesos pedagógicos que adelanta.

- Las diferentes formas de atención al niño deben facilitar la convivencia y la vivencia internadelademocraciaydelaparticipación activa; deben ser un espacio abierto a la participacióndelacomunidad.Yaqueesenla socialización, que los niños y las niñas se van formandocomociudadanoscomprometidos con su propia historia y partícipes de la vida de sus comunidades.

\section{Categoría 4. Comunidades educativas}

Tradicionalmente la educación de los niños ha estado circunscrito al momento en que estos ingresan a las instituciones de educación formal y se desconoce la influencia de otras instancias encargadas de brindar atención, bienestar y experiencias sociales, verbales, expresivas y de aprendizaje que han de definir su futuro desempeño, es decir, se desconocía la influencia de la comunidad que proporciona elementos y herramientas que favorecen lo cognitivo, lo comunicativo, lo social, lo afectivo y lo corporal.

Según Salazar (2001), citado por Posada, "actualmente se llama comunidad educativa al conjunto de la familia, la escuela, la sociedad y los medios de comunicación, que rompen con la idea de confinar la educación únicamente al ámbito de la escuela como era costumbre en nuestro medio (...). Ello quiere decir que tiene objetivos comunes en el proceso educativo y que sus acciones específicas son complementarias” (p. 100). Lo anterior implica mirar la educación inicial como un todo, conformado no solo por la labor del docente y la institución, sino donde se hace partícipe a la familia y la comunidad en su conjunto para lograr aprendizajes significativos, que favorezcan el adelanto de sus capacidades físicas, psicológicas y sociales, y que generen acciones coherentes con las características individuales, culturales, históricas, étnicas y de género que rodean al niño, y que, desde la gestación, determinan las condiciones con las que enfrentarán el mundo.

Cada uno de los entornos (familiar, comunitario e institucional) en los que se encuentra inmerso cada niño, debe estar 
enmarcado por una atención integral que no abarque única y exclusivamente la educación inicial, sino, también, la protección, la salud, la alimentación, entre otros, y que reconozca que los niños son sujetos titulares de derechos. Es importante reconocer cuál es el papel de cada uno de los entornos y los agentes educativos o significativos dentro de la formación a la primera infancia, que se pueden clasificar en:

\section{- Contexto familiar:}

El Ministerio de la Protección Social (2007) señala que "es el contexto natural para el desarrollo integral de los niños y las niñas de 0 a 6 años, está orientado por los parámetros del amor, la ternura y el reconocimiento de la dignidad y los derechos de todos sus miembros" (p. 25). Como núcleo fundamental de la sociedad, su carácter formativo debe estar orientado a favorecer el afianzamiento de la personalidad, la autonomía, el respeto por la cultura y la responsabilidad social que adquiere por ser un ciudadano reconocido ante la ley.

La familia, a través de las prácticas de crianza, las cuales, como plantea Aguirre (2000): "son acciones que se orientan a garantizar la supervivencia del infante, a favorecer su crecimiento y evolución psicosocial, y a facilitar el aprendizaje de conocimientos que permitan al niño reconocer e interpretar el entorno que le rodea" (p. 6). Deben propender por generar espacios significativos, llenos de experiencias desde lo afectivo, lo social, lo comunicativo y lo cognitivo, que favorezcan aprendizajes que lleven a que su desarrollo sea integral y multidimensional, teniendo en cuenta el entorno social, cultural y las normas presentes en cada una para que sea un acompañamiento responsable e intencional.

\section{- Contexto institucional:}

Su función debe estar centrada en propiciar espacios para la educación, los aprendizajes y el cuidado responsable; además de promover la socialización de los actores involucrados en la formación (familia, comunidad, sociedad, Estado, niños, etc.). Es un espacio creado para potenciar al máximo la intencionalidad educativa, enmarcada dentro de unos parámetros para garantizar una educación con calidad, éstos son: el Proyecto Educativo Institucional (PEI), el currículo, los materiales didácticos, las ayudas educativas, personal interdisciplinario, entre otros aspectos que hacen de la institución un espacio de socialización y de construcción de aprendizajes significativos.

Pero no solo es el contexto de la escuela la encargada de brindar una atención integral, sino que dentro del contexto institucional cabe mencionar otras instancias prestadoras de servicios que benefician el crecimiento integral de los niños, entre las que se encuentran las instituciones, donde se brindan apoyos referentes a los servicios de salud, nutrición, cuidado, recreación y educación, que permiten la adquisición de aprendizajes por medio de la socialización, tanto con los adultos y profesionales presentes como con los demás niños.

\section{- Papel del docente:}

Según el Ministerio de Educación Nacional de Colombia, el rol del educador es el de orientar "un proceso de formación, enseñanza, aprendizaje de los educandos, acorde con las expectativas sociales, culturales, éticas $\mathrm{y}$ 
morales de la familia y la sociedad". Su función incluye realizar un diagnóstico, que permita identificar necesidades y fortalezas, tanto de los niños, como de la comunidad, trabajando sobre ellas, mediante la planificación, ejecución de actividades y estrategias, basadas en los intereses de los niños, que propicien la indagación, la exploración y la construcción significativa de los aprendizajes.

\section{- Contexto comunitario y social:}

La comunidad y el contexto social son un sistema macro que abarca los demás entornos (familiar e institucional) y a los actores o agentes educativos inmersos dentro del aprendizaje, lo cual permite ver al sujeto como un ser social, inmerso imbuido en una cultura, una historia, unos valores, unas normas, etc., que hacen que la comunidad, en su conjunto, busque un bien común antes que un bien individual.

Es por esto que el contexto comunitario y social tiene un papel importante dentro de una comunidad educativa, ya que es en estos escenarios donde el niño podrá poner en práctica y en evidencia sus aprendizajes y experiencias para la transformación social. Como lo describe el Congreso de la República de Colombia: "la sociedad es responsable de la educación con la familia y el Estado. Colaborara con éste en la vigilancia de la prestación del servicio y en el cumplimiento de su función social” (1994, p. 19, art. 8).

La comunidad educativa es, entonces, un conjunto de contextos y agentes que hacen posible garantizar una educación inicial con calidad y una atención integral que propicia espaciosdediálogo,concertación,participación, convivencia y construcción cooperativa de un aprendizaje-enseñanza, basado en los derechos de los niños, en sus necesidades, intereses, gustos y, sobre todo, en la formación de seres transformadores de la sociedad, con una formación de valores morales y éticos desde la primera infancia, que conlleven a una cultura democráticayalaformación deunaciudadanía, responsable y comprometida con la educación como un derecho y como función social.

Dentro de la comunidad educativa es necesario resaltar la importancia que adquieren los niños como el centro del aprendizajeenseñanza, pues son ellos los encargados de darle sentido a la educación y, por ende, a la comunidad educativa en general. El niño debe ser un sujeto activo, inquieto por el saber, el conocer y el hacer, investigador, crítico, reflexivo y consciente de su propio proceso; por ello, las acciones que se lleven a cabo deben estar pensadas en los intereses y necesidades de los niños a los cuales se está atendiendo y formando.

De este modo, toda comunidad educativa está llamada a ser responsable y trabajar corresponsablemente en la educación y atención integral de los niños, dado que cada uno de los miembros deberá participar en lo que conduzca a conocer y fortalecer el rol que la sociedad le reclama como garante de lo que ocurre con los niños en los primeros años de vida, ya que si les ofrecen atención oportuna y de calidad, probablemente crecerán y desarrollarán todas sus capacidades, habilidades y destrezas, que permitan una vida plena tanto presente como futura.

En consecuencia, como lo plantea el MEN (2009): 
Los agentes educativos responsables de la educación para la primera infancia, deben adelantar procesos educativos intencionados, pertinentes y oportunos generados a partir de los intereses, características y capacidades de los niños y las niñas, con el fin de promover el desarrollo de sus competencias liderando un cambio cultural que impulse prácticas pedagógicas acordes con este marco. Por lo tanto, se espera que los agentes educativos asuman su papel como promotores del desarrollo de competencias, a partir de la observación, el acompañamiento intencionado, la generación de espacios educativos significativos y el conocimiento de quiénes son aquellos niños y niñas ( $\mathrm{p}$. 20).

\section{Conclusiones}

Los aprendizajes que se les brinden a los niños en su primera infancia, desde una atención y formación integral, y enmarcados dentro de una educación inicial, deben permitir la construcción de los cimientos de su desarrollo humano, por tal razón es menester contribuir cuidadosamente en la formación de su identidad cultural, su adecuada relación con el medio familiar y comunitario, con las personas que le rodean, la configuración de su sentido de pertenencia, sus valores y actitudes, su seguridad y autoestima, su personalidad, su propia lengua y su propia vida cultural, lo que permite atender a los niños, independientemente de su etnia, género, condición socioeconómica, religión, o ideología.

Por otra parte, la construcción del presente artículo, fundamentado en el marco conceptual del proyecto mencionado, permitió fortalecer en el ámbito personal, las habilidades investigativas, escriturales, reflexivas y criticas, de los diferentes aspectos que están implicados en la práctica, puesto que no solo se cumplió con un deber sino con la consolidación, como profesional de la educación, que en el ejercicio de la misma permitirá la aplicación de lo aprendido, con el fin de contribuir, responsable y respetuosamente, a la educación inicial con calidad de los niños, para responder a sus derechos y a sus necesidades de descubrir, indagar y conocer el mundo que los rodea. Además, la conceptualización del marco y del artículo, posibilitó la profundización en un saber específico, puesto que se tuvieron que retomar teorías, enfoques, aportes de distintas ciencias, entre otros aspectos que giraron en torno a los aprendizajes relevantes o significativos de la primera infancia, como base fundamental de su desarrollo integral y multidimensional.

\section{Referencias}

Aguirre, E. (2000). Socialización y Prácticas de Crianza. En Aguirre \& Durán. Socialización: Prácticas de Crianza y Cuidados de la Salud. Bogotá: CESUniversidad Nacional de Colombia.

Cajiao, Francisco. (2005). El universo de las prácticas escolares. En Instrumentos para escribir el mundo. Escritura, lectura y política en el universo escolar. (73-124). Bogotá: Editorial Magisterio.

CollCésar.Desarrollopsicológicoyeducación. 1. Psicología evolutiva. (133-147). Madrid: Alianza Editorial.

Congreso de la República de Colombia. (1994). Ley General de Educación. Ley 115. Bogotá: EL TREBOL Ltda. ------. 
(2006). Código 1098. Ley de la Infancia y la Adolescencia. Bogotá: Editorial Unión Ltda.

Correa, Jorge. (2010). Núcleo de investigación y práctica. Sustento de la formación en investigación. Medellín: Tecnológico de Antioquia. Facultad de Educación y Ciencias Sociales.

De Zubiría Samper, Julián. (1999). Los modelos pedagógicos. Tratado de pedagogía conceptual. Bogotá: Editorial Fundación Alberto Merani. --.--. (2002). Los modelos pedagógicos. Hacia una pedagogía dialogante. Bogotá: Cooperativa Editorial Magisterio.

Marchesi Álvaro \& César Coll. (1999). Desarrollo psicológico y educación. 1. Psicología evolutiva. (23-72). Madrid: Alianza Editorial.

Ministerio de Educación Nacional. (1995). Lineamientos curriculares de Preescolar. Bogotá: Magisterio. ------.. (2007). Política Educativa para la Primera Infancia. Bogotá. [Versión digital].-----.. (2009). Guía Operativa para la Prestación del Servicio de Atención Integral a la Primera Infancia. Bogotá. [Versión digital].------. (2009). Documento $\mathrm{N}^{\circ} 10$. Desarrollo Infantil y Competencias en la Primera Infancia. Bogotá. [Versión digital].

Ministerio de la Protección Social, Ministerio de Educación Nacional, Instituto Colombiano de Bienestar Familiar \& DNP-DDS-SS. (2007). Documento Conpes 109, Política Pública Nacional de Primera Infancia, "Colombia por la Primera Infancia”. [Versión digital].
Ortiz, José M., Fuentes, María J. \& López, Félix. (1999). Desarrollo psicológico en la primera infancia. Desarrollo socio-afectivo en la primera infancia. En Jesús Palacios, Álvaro Marchesi \& César Coll. Desarrollo psicológico y educación. 1. Psicología evolutiva. (151-175). Madrid: Alianza Editorial.

Palacios,Jesús.(1999).Introducciónalahistoria, los conceptos y los métodos. Psicología evolutiva:concepto,enfoques, controversias y métodos.

Papalia, Diane. (1998). Psicología del desarrollo. Buenos Aires: MGraw-Hill.

Palacios, Jesús. (1999). Desarrollo psicológico en la primera infancia. Desarrollo cognitivo durante los dos primeros años. En Jesús Palacios, Álvaro Marchesi \& César Coll. Desarrollo psicológico y educación. 1. Psicología evolutiva. (103128). Madrid: Alianza Editorial.

Palacios, Jesús \& Mora, Joaquín. (1999). Desarrollo psicológico en la primera infancia. Crecimiento físico y desarrollo psicomotor hasta los 2 años. En Jesús Palacios, Álvaro Marchesi \& César Coll. Desarrollo psicológico y educación. 1. Psicología evolutiva. (p. 81-97). Madrid: Alianza Editorial.

Posada, Jorge. (2001). Notas sobre Comunidad Educativa. En: Avellaneda, A., Zapata, G. \& otros, Notas sobre Comunidad Educativa y Cotidianidad Escolar. (87119). Bogotá: Universidad Nacional de Colombia Programa RED. 
Vila, Ignasi. (1999). Desarrollo psicológico en la primera infancia. Los inicios de la comunicación, la representación y el lenguaje. En Jesús Palacios, Álvaro Marchesi.

\section{Cibergrafía}

Amei -Waece. (2005). El campo y concepciones fundamentales de la educación de la primera infancia. Recuperado de http://www.waece.org/ web_nuevo_concepto/indice.htm.

Barreda, Pedro. (2000). En periodo crítico para el aprendizaje. Recuperado de http:// www.pediatraldia.cl/01BODEGA2/ perio_crit_aprendi.htm.

De La Barrera, María \& Donolo, Danilo. (2009). Neurociencias y su importancia en contextos de aprendizaje. Recuperado de http://www.revista.unam.mx/vol.10/ num4/art20.htm.

Ministerio de Educación Nacional. (S.F). Concepto de Función Docente. Recuperado de http://www. mineducacion.gov.co/1621/article-80258. html.

Ministerio de Educación Nacional, República de Colombia. (2006). Colombia por la Primera Infancia". Recuperado de http://www.mineducacion.gov.co/ primerainfancia/1739/articles-177828 archivo_pdf_politica2006.pdf.

Reveco, Ofelia. (2006). La búsqueda del desarrollo integral del niño y la niña: Aportes desde la Educación Infantil.
Recuperado de http://www.waece.org/ textosmorelia/ponencias/reveco.htm .

\section{Documento}

González Agudelo, Elvia María. "Una visión holística de la pedagogía contemporánea”. 